\title{
EXPERIMENTAL INVESTIGATION ON M-SAND AND BASALT FIBER IN M25 GRADE CONCRETE
}

\author{
Ms.S.Dhivya ${ }^{1}$,N.P.Srinivasan ${ }^{2}$, M.Jaya Lakshmi ${ }^{3}$, J.Keerthana ${ }^{4}$, S.Parkavi ${ }^{5}$ \\ 1,3,4,5 Department of Civil Engineering, KPR Institute of Engineering \& Technology (Autonomous), Coimbatore \\ ${ }^{2}$ M.Kumarasamy College of Engineering, Karur \\ 1dhivyaengg11@gmail.com, 2npscem14@gmail.com.
}

\begin{abstract}
Concrete is the majorly used materials in all type of construction activites. It need a quality sources for obtaining good quality. It can achieve by only proper usage of these at appropriate quantities. Basalt fiber is a fiber when added provides an additional strength. The work carried in this project, replace fine aggregate with M-sand and basalt fiber as an additive to cement in various percentages. The determination of the compressive, flexural and tensile strength of M25 grade concrete is studied. The fine aggregate is completely replaced with $\mathrm{M}$ sand and basalt fiber is added in $0 \%, 0.5 \%, 1 \%$ and $1.5 \%$. Thus the changes in their compressive, flexural and tensile strength is observed for $\mathbf{1 4}$ days and 28 days and results are formulated and the optimum content of basalt fiber to be utilized for production of quality concrete is founded.
\end{abstract}

Keywords: Basalt Fiber, M-Sand, River Sand, Fiber Reinforced Concrete.

\section{Introduction}

The usage of fibers in concrete has been increasing in recent years due their high strength and durability. There are two types of fibers used for the manufacturing of fiber reinforced concrete. They are, natural and artificial fibers. Fibers can be used in powder form or in chopped form depend upon the availability of Materials. They increase the hardened characteristics of the concrete. Fiber available from Basalt is a natural fiber obtained from volcanic rocks.

Now a days there has been more demand for river sand as dredging of river beds because economical imbalance and it lead to increase of cost of river sand. It is obtained from crushing of granite stones and grinded to the required size. It can be put to use as an alternative of river sand partially. To maintain the strength and conserve the nature by using these materials in concrete.

\section{Material Investigation}

\subsection{Cement}

Cement is the most important material as its acts as a binding material which binds all material together in the concrete mixture without it is not possible to make concrete. This project work is done with the Portland cement of 53 grade cement to acquire strength properties of Concrete. Physical properties of cement is done as per IS: 456-2000 and in table 1 the results are tabulated.

Table 1: Properties of Cement

\begin{tabular}{|l|l|}
\hline OPC 53 Cement Properties \\
\hline $\mathrm{Sg}$ & 3.13 \\
\hline $\mathrm{R}$ & $94 \%$ \\
\hline Water & $29 \%$ \\
\hline In.Settime $\left(\mathrm{T}_{2}-\mathrm{T}_{1}\right)$ & 35 \\
\hline F.Set time $\left(\mathrm{T}_{3}-\mathrm{T}_{1}\right)$ & 450 \\
\hline
\end{tabular}

*(Sg-Specific gravity, R-Fineness)

\subsection{Fine aggregate}

The Manufactured sand is known as M-Sand. As the size of M - Sand is less than $4.75 \mathrm{~mm}$. It act as a best alternate of river sand for concrete construction. M-sand is from zone II which is available locally in the market is adopted as F.A in our project. Physical properties of $\mathrm{M}$-sand is done as per IS: 383(1970) and IS: 2386 and in table 2the results are shown.

Table 2: Properties of M-Sand

\begin{tabular}{|l|l|}
\hline M-Sand Properties \\
\hline Grade & Zone II \\
\hline Sg & 2.54 \\
\hline$\%$ Absorption of water & 1 \\
\hline FM & 2.16 \\
\hline
\end{tabular}

\subsection{Coarse Aggregate (C.A)}

Granites are crushed to size of $20 \mathrm{~mm}$ is mixed as coarse aggregate in this concrete mixture. Physical properties of coarse aggregate test are done as per as IS: 383(1970) and IS: 2386 and in table 3 the results are shown.

Table 3: Properties of Coarse Aggregate

\begin{tabular}{|l|l|}
\hline C.A Properties & $20 \mathrm{~mm}$ \\
\hline Size & 2.47 \\
\hline Sg & 7.15 \\
\hline FM & 0.3 \\
\hline$\%$ Absorption of water &
\end{tabular}




\subsection{Water}

Water used is to check the PH level should nearly 7 according to IS: 456-2000. For this project the water from the concrete lab is used.

\subsection{Basalt fiber}

Basalt fiber is one kind of naturally available fiber obtained through basalt rock which is a type of igneous rocks and it is used as an additive to cement to improve the mechanical characteristics of concrete mixture. In our experiment, the basalt fibers are added in $0 \%, 0.5 \%, 1 \%$ and $1.5 \%$. The properties of basalt fiber based on the manufacture is given in table 4 ,

Table 4: Properties of Basalt fiber

\begin{tabular}{|l|l|l|l|}
\hline Property & Unit & Value & Tolerance \\
\hline Density & $\mathrm{Kg} / \mathrm{m}^{3}$ & 2.70 & $+/-5 \%$ \\
\hline Moisture & $\%$ & 0.1 & $+/-0.04$ \\
\hline Melting point & ${ }^{\circ} \mathrm{C}$ & 1340 & $+/-99$ \\
\hline Diameter & $\mu \mathrm{m}$ & 13 & - \\
\hline Length & $\mathrm{mm}$ & $6-18$ & $+/-5 \%$ \\
\hline
\end{tabular}

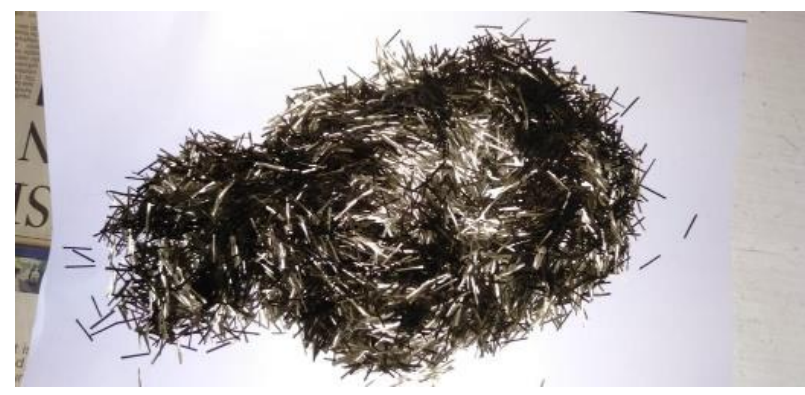

Fig-1: Basalt fiber.

\subsection{M-sand}

As a civil engineer it our duty to develop the world without affecting the environment we live in. In recent years manufactured sand is utilized as an alternate for river sand due to its demand. It is the product obtained from crushing granite stones. Then it is washed and graded to required size to use a construction material. Due to its availability its cost is considerably low when compared to the river sand. As it is manufactured we can get the required size. As per IS: 383 zone II is usually preferred.

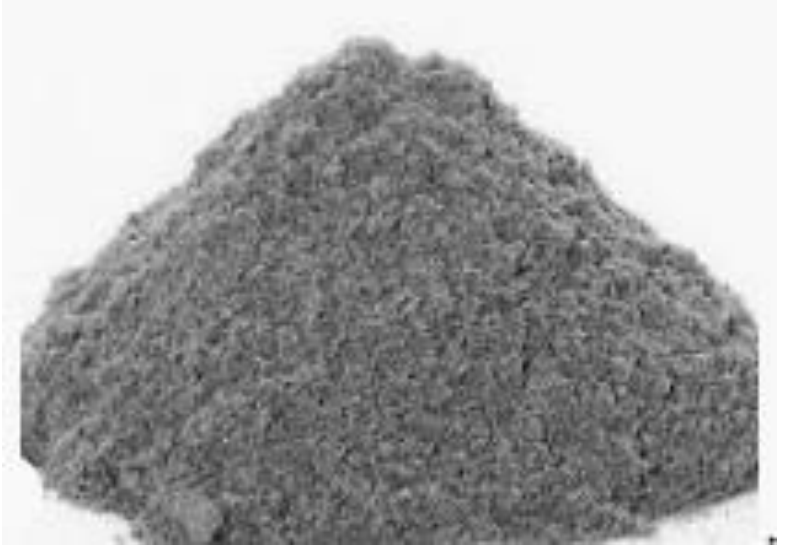

Fig-2: M Sand

\section{Mix Design\& Fiber Content}

\subsection{Concrete Mix Proportion}

Quality of the concrete determines the strength achieved in structures and it is also very important to design it with utmost precision. In our project study we use M25 grade of concrete. The mixing proportion is available using IS: 10262-2009. Table 5 shows the obtained proportion for M 25 concrete.

Table 5: M25 Concrete-Mix Proportion

\begin{tabular}{|l|l|l|l|l|}
\hline & Cement & $\begin{array}{l}\text { FA } \\
(\mathbf{M} \\
\text { Sand })\end{array}$ & CA & $\begin{array}{l}\text { W/C } \\
\text { Ratio }\end{array}$ \\
\hline Ratio & 1 & 1.7 & 2.7 & 0.5 \\
\hline $\begin{array}{l}\text { Weight } \\
\left(\mathrm{kg} / \mathrm{m}^{3}\right)\end{array}$ & 394 & 689 & 1094 & 197 \\
\hline
\end{tabular}

\subsection{Fibre Content}

In this project the basalt fiber is added in $0 \%, 0.5 \%, 1 \%$ and $1.5 \%$. The fiber content for each percentage is given in table 6 .

Table 6: Fiber Content.

\begin{tabular}{|l|l|}
\hline Proportion (\%) & Fiber content $(\mathbf{g})$ \\
\hline 0 & - \\
\hline 0.5 & 162 \\
\hline 1 & 324 \\
\hline 1.5 & 485 \\
\hline Total fiber content & 971 \\
\hline
\end{tabular}

\section{Mechanical Characteristics Of Concrete}

\subsection{Compressive Strength}

The strength of a material or structure is the applied load to area of the specimen to check the resist load applied on its surface. Normally for testing the compressive strength, the specimen with size $5.9 \times 5.9 \times 5.9$ inches is casted and cured for respective days then it is place in Compressive testing machine and execute the load gradually increasing on the surface. After the application of the load the specimen starts to crush and the ultimate load is identified. The compressive strength is obtained by,

Compressivestrength $=\frac{P}{A}$ Where

$\mathrm{P}$ - Ultimate load, N

A - Area of Cross- Section, $\mathrm{mm}^{2}$ 


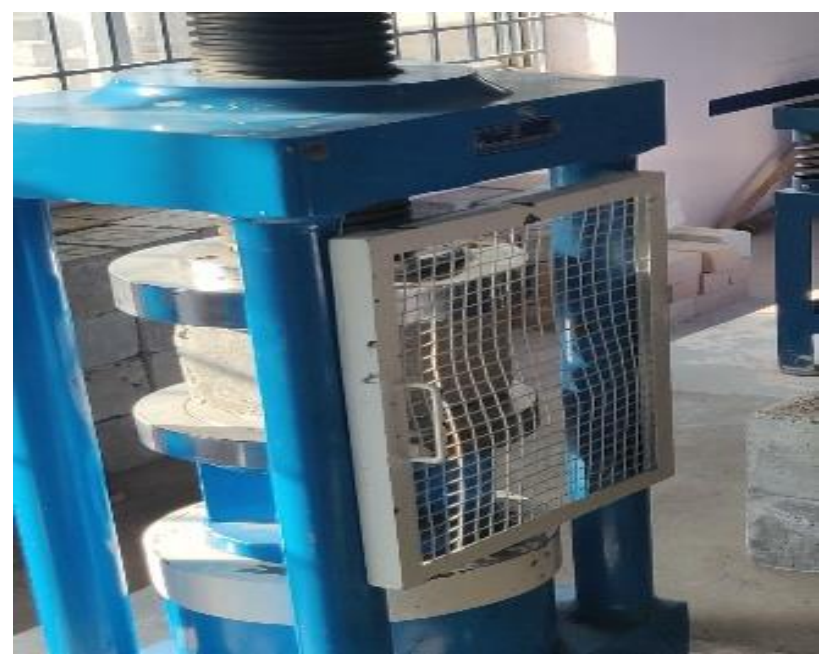

Fig-3: Compressive Test on concrete

4.2 Splitting Tensile Strength

A cylindrical specimen of diameter 5.9 inch and height 11.81 inch is used. The specimen is cured and kept under split tensile test machine and load is noted till the specimen breaks.

Split Tensilestrength $=\frac{(2 P)}{(3.14 \times D X L)}$ Where,

P- Load at Failure

$\mathrm{D}=$ Specimen Diameter

$\mathrm{L}=$ Specimen Length

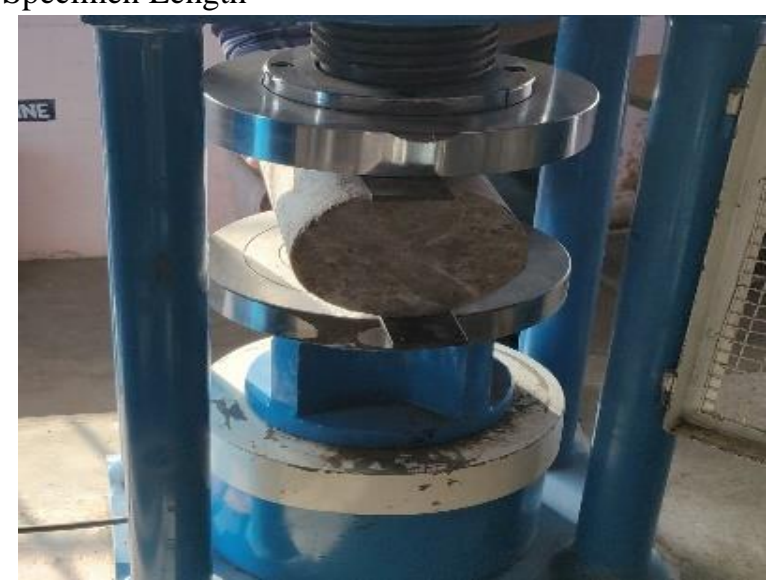

Fig-4: Split Tensile Test of concrete

\subsection{Flexural Strength Test on Concrete}

The specimen of size $5.9 \times 3.93 \times 3.93$ inches is casted and tested. The specimens are cured and kept under the flexural machine and the load is applied gently until the specimen breaks and obtain final load.

Flexuralstrength $(\mathrm{Mpa})=\frac{(P X L)}{\left(B X D^{2}\right)}$

Where,

$\mathrm{P}=$ Load at Failure

$\mathrm{L}=$ beam Length

$\mathrm{B}=$ beam Breadth

$\mathrm{D}=$ beam Depth

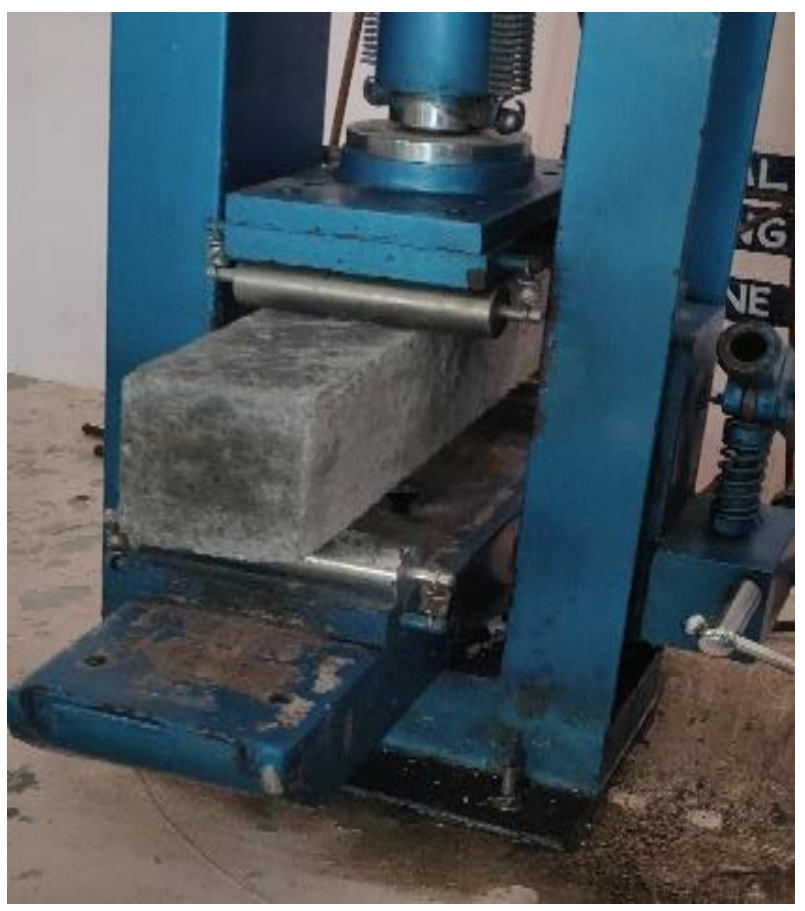

Fig-5: Test for flexural strength of concrete

\section{Discussion Of Results}

4.1 Compressive Strength

The compressive strength obtained for both 14 days and 28 days as shown in table 7.The strength achieved on 14 days shows a rise in strength achieved on 28days. Thus shows there is a increase in the compression strength of the specimen.

Table 7: Compressive strength of specimens at

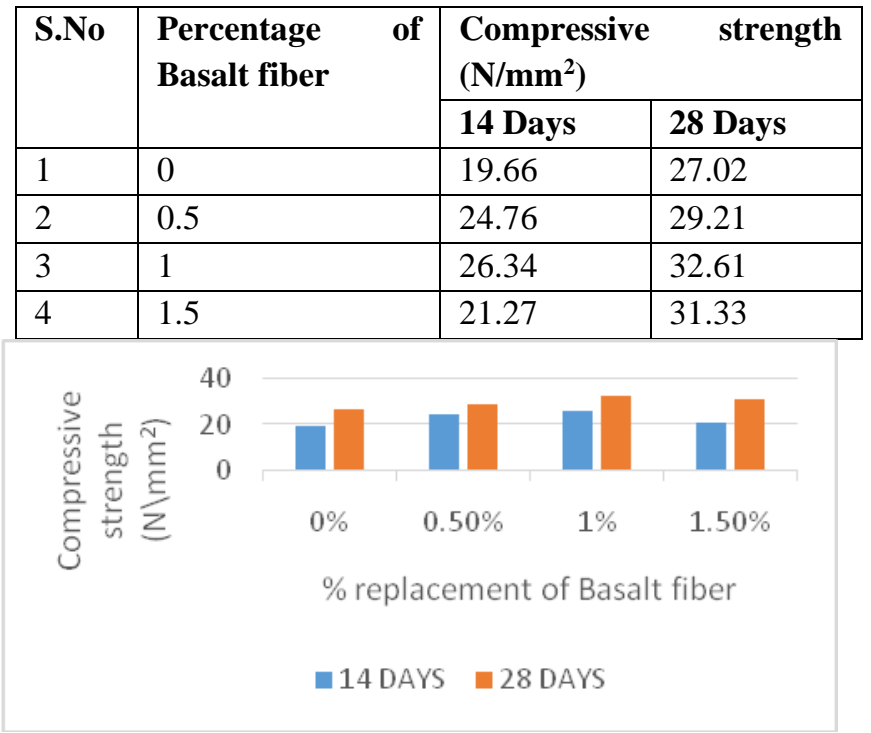

Fig-5: Compressive strength of \%replacement

The compressive strength shown in Fig 5 has been increased when the control concrete and maximum compressive strength is noted on adding $1 \%$ of basalt fiber and when increased the compressive strength starts reducing.

4.2 Splitting Tensile Strength

The split tensile strength obtained for both 14 days and 28 days as shown in table 8.The strength achieved on 14 days 
shows a rise in strength achieved on 28days. Thus shows there is a increase in the split tensile strength of the specimen.

Table 8: Splitting Tensile strength of specimens

\begin{tabular}{|l|l|l|l|}
\hline S.No & \multirow{2}{*}{$\begin{array}{l}\text { Percentage of } \\
\text { Basalt fiber }\end{array}$} & \multicolumn{2}{|l|}{$\begin{array}{l}\text { Splitting Tensile strength } \\
\left(\mathbf{N} / \mathbf{m m}^{2}\right)\end{array}$} \\
\cline { 3 - 4 } & & 14 Days & 28 Days \\
\hline 1 & 0 & 2.142 & 2.63 \\
\hline 2 & 0.5 & 2.23 & 2.85 \\
\hline 3 & 1 & 2.38 & 3.2 \\
\hline 4 & 1.5 & 2.32 & 2.87 \\
\hline
\end{tabular}

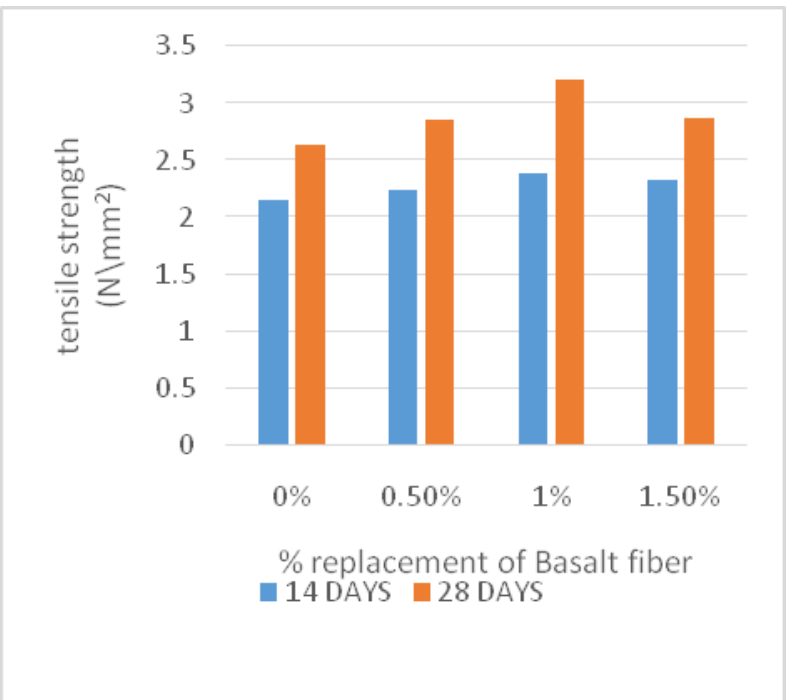

Fig-6 : Tensile strength of \% replacement Basalt Fiber The Fig- 6 shows the tensile strength is increased to the control concrete and maximum tensile strength is achieved for $1 \%$ of basalt fiber and on further increasing the tensile strength starts reducing.

\subsection{Flexural Strength}

Table 9: Flexural strength of specimens at $14 \& 28$ Days

\begin{tabular}{|l|l|l|l|}
\hline S.No & $\begin{array}{l}\text { Percentage of } \\
\text { Basalt fiber }\end{array}$ & $\begin{array}{l}\text { Avg flexural strength } \\
\left(\mathrm{N} / \mathrm{mm}^{2}\right)\end{array}$ \\
\cline { 3 - 4 } & & 14 Days & 28 Days \\
\hline 1 & 0 & 3.14 & 3.65 \\
\hline 2 & 0.5 & 3.84 & 4.22 \\
\hline 3 & 1 & 4.1 & 4.54 \\
\hline 4 & 1.5 & 3.86 & 4.09 \\
\hline
\end{tabular}

The flexural strength obtained for the both 14 days and 28 days as shown in table 7.The achieved strength on 14 days shows a gradual increase in strength achieved on 28days. Thus shows there is increase in the flexure strength of the specimen.

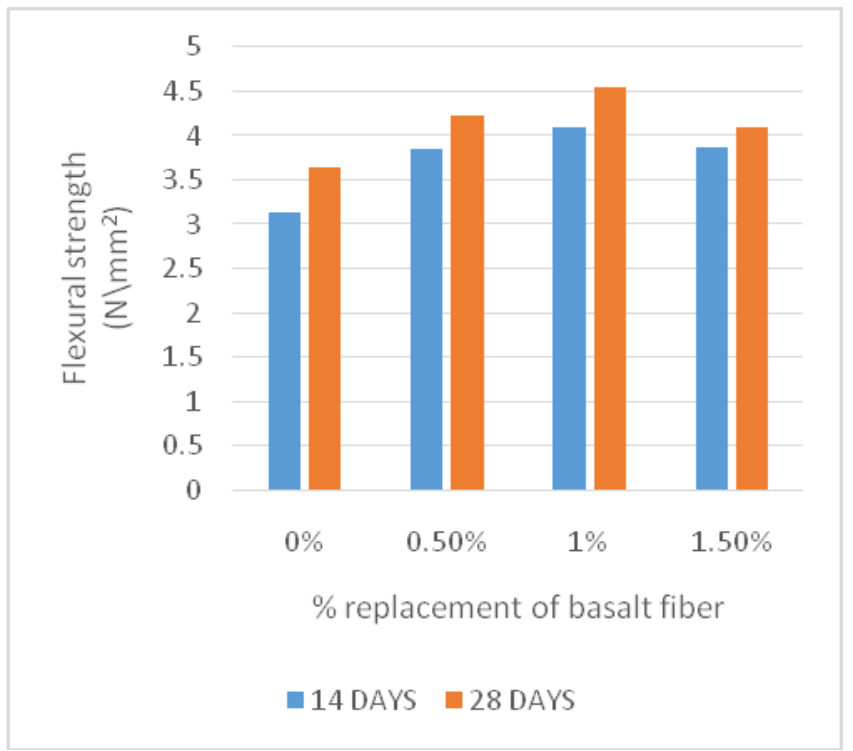

Fig-7: Flexural strength of \% replacement Basalt Fiber The Fig-7 shows the flexural strength is increased to the control concrete and maximum Flexural strength is achieved for $1 \%$ of basalt fiber and on further increasing the flexural strength starts reducing.

\section{Conclusion}

From the above experimental carried the following conclusions are made

$>\quad$ M-Sand replacement has noeffecton the strength of the concrete.

$>\quad$ The availability of M-sand is easy and cheaper than River sand and can be used as alternative for river sand.

$>\quad$ Optimum value basalt fiber is found to be $1 \%$ on adding more than $1 \%$ the value starts reducing.

$>\quad$ The basalt fiber when added as an additive it decreases the workability.

$>\quad$ From the result of compressive strength achieved for 28 days with basalt fiber in $1 \%$ is increased by $23.80 \%$ than the control specimen.

$>\quad$ From the result of split Tensile strength achieved 28 days with basalt fiber in $1 \%$ is increased by $34.45 \%$ than the control specimen.

From the result of Flexural strength achieved 28 days containing basalt fiber in $1 \%$ is increased by $12.07 \%$ than the control specimen.

It also shows the strength of concrete get increased with number of days.

\section{References}

[1] Alan J. Brookes, "Cladding of Buildings", Third Edition Published 2002, (pp 82)

[2] Bang Yeon Lee (2015), "Bonding properties of basalt fiber and strength reduction according to fiber orientation", MDPI journal of materials, pp.67196727. 
[3] J.G. Ferreira, F.A. Branco 2005, "Structural application of GRC in telecommunication towers",Construction and Building Materials Journal, Published August 2005.

[4] Cory High (2015), "Use of basalt fibers for concrete structures", construction and building materials, pp.37-46.

[5] John Branston (2016), "Mechanical behavior of basalt fiber reinforced concrete", construction and building materials, pp.878-886.

[6] Nayan Rathod (2015), "Basalt fiber reinforced concrete", International Journal of Science and Research Vol. 4, pp.359-361.

[7] Wael Alnahhal, "Flexural behavior of basalt fiber reinforced concrete beams with recycled concrete coarse aggregate", construction and building materials, pp.165-178. 